Gut, 1973, 14, 649-652

\title{
A further case of chronic ulcerative enteritis
}

\author{
B. K. ARMSTRONG, R. K. AMMON, L. R. FINLAY-JONES, R. A. JOSKE, AND \\ A. B. VIVIAN
}

From the Departments of Medicine and Surgery, University of Western Australia, and the Departments of Pathology, Royal Perth Hospital, Perth, Western Australia

SUMMARY A further case of chronic ulcerative enteritis is presented. In this case there was clear evidence that the ulcerative process was superimposed upon atrophic jejunitis with malabsorption. The development of ulceration produced a picture of small bowel obstruction and its differential diagnosis from neoplasm was not possible without laparotomy.

Chronic ulcerative enteritis is a rare disease. Although it was first described in 1949, a review in 1971 by Moritz, Moran, and Patterson included only 25 cases. The majority of these were from North America, but some have been reported from Australia and Europe (Goulston, Skyring, and McGovern, 1965; Davidson, 1969).

The disease is characterized by multiple chronic benign ulcers of the small bowel, most frequently the jejunum, with resultant colic, fever, diarrhoea, and later progression to intestinal strictures. It is closely associated with intestinal malabsorption and atrophic jejunitis, and there is debate whether the ulceration precedes or follows this lesion. Most authors favour the latter possibility.

This paper reports a further case of chronic idiopathic ulcerative enteritis because of the rarity of this disease and the problems of differential diagnosis and management which it presented. In this instance there is clear evidence that malabsorption was present before the development of intestinal ulceration.

\section{Case Report}

A 58-year-old Englishwoman presented to a surgical unit at another hospital in July 1968. For 20 years she had had epigastric pain and flatulence, followed by progressive lassitude and diarrhoea for seven years. Her presentation followed anorexia and weight loss (54 to $43 \mathrm{~kg}$ ) for three months, and nausea, vomiting, and colicky lower abdominal pain for two months. There was no significant previous history except for infantile rectal prolapse at 12 months of age.

Received for publication 3 May 1973.
Examination at this time showed signs of wasting, generalized increased cutaneous pigmentation, and digital clubbing. The abdomen was distended and 'doughy' to palpation. There was moderate peripheral oedema.

A barium enema showed a narrow irregular segment of sigmoid colon.

At laparotomy several sigmoid diverticula were found, but no resection was undertaken. The small bowel appeared normal.

Her symptoms persisted after operation, and she developed tetany. Further investigation was therefore undertaken. This revealed atrophic jejunitis and intestinal malabsorption.

The haemoglobin was $11.5 \mathrm{~g}$ per $100 \mathrm{ml}$, and a blood film showed macrocytosis and some hypersegmented polymorphs. The white cell count was 5300 per cmm; ESR, $1 \mathrm{~mm}$ drop in one hour; serum vitamin $B_{12}, 550 \mathrm{pg}$ per $\mathrm{ml}$; serum folate, $1.0 \mathrm{ng}$ per $\mathrm{ml}$; serum potassium, $2.7 \mathrm{~m}$-equiv per 1; serum albumin, $1.7 \mathrm{~g}$ per $100 \mathrm{ml}$; serum globulin, $2.7 \mathrm{~g}$ per $100 \mathrm{ml}$; plasma carotene, $10 \mu \mathrm{g}$ per $100 \mathrm{ml}$; faecal fat excretion (three days), $19.2 \mathrm{~g}$ per day; d-xylose absorption ( $5 \mathrm{~g}), 0.22 \mathrm{~g}$ in fivehour urine. Other biochemical results were within normal limits. A barium meal showed dilated loops of small bowel and coarse jejunal mucosal folds. Jejunal biopsy showed subtotal villous atrophy.

Treatment was begun with a gluten-free diet and supplements of potassium (as Slow-K and Potavescent), calcium (as calcium Sandoz), and folic acid. However, diarrhoea persisted and her weight fell to $31 \mathrm{~kg}$ in May 1969. There was no improvement with successive short courses of oral tetracycline, pancreatic extract, and prednisone. In June 1969 potassium chloride therapy was stopped.

A second laparotomy was performed at this 
time. No macroscopic abnormality was apparent. However, after this the diarrhoea ceased and her weight increased to $43 \mathrm{~kg}$. She remained in fair health on a gluten-free diet for 18 months.

Further symptoms developed in May 1971, with the onset of anorexia, postprandial lower abdominal colic, and loss of $9 \mathrm{~kg}$ weight but without a recurrence of diarrhoea. Relevant investigations included ESR, $33 \mathrm{~mm}$ drop in one hour; d-xylose absorption $(25 \mathrm{~g}), 1.3 \mathrm{~g}$ in five-hour urine; faecal fat excretion (three days), $7.9 \mathrm{~g}$ per day. Barium studies of the small bowel using intravenous metoclopramide showed dilatation of the proximal jejunum with an obstructing stricture approximately $90 \mathrm{~cm}$ from the duodenojejunal flexure (fig 1).

A further laparotomy was therefore undertaken in July 1971 . There were multiple, irregular, tumourlike thickenings of the small bowel, extending from $25 \mathrm{~cm}$ distal to the duodenojejunal flexure to within $100 \mathrm{~cm}$ of the ileo-caecal valve. The largest and most proximal of these was the site of an incomplete small bowel obstruction. A macroscopic diagnosis of malignant obstruction was made, and the obstruction bypassed by enteroanastomosis, biopsies being taken from the suspected tumours and jejunal and ileal mucosa. Examination of these did not show neoplastic tissue, so a resection of $62 \mathrm{~cm}$ of small bowel, including the obstructing lesions, with end-to-end anastomosis was performed a few days later. The postoperative course was uneventful.

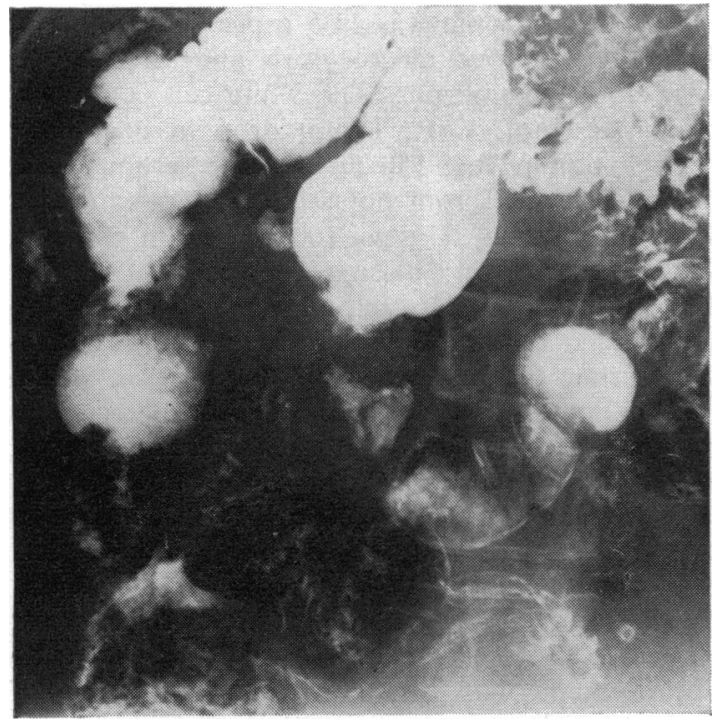

Fig 1 Chronic ulcerative enteritis. Portion of barium examination of small intestine showing dilated loops of small bowel with partial obstruction in the upper jejunum.
Examination of the resected specimen showed two large deep circumferential ulcers $4 \mathrm{~cm}$ and $3 \mathrm{~cm}$ in diameter, as well as 13 other shallow ulcers distributed in irregular fashion along the mucosa (fig 2). The latter ranged in size from $3 \mathrm{~cm}$ to $3 \mathrm{~mm}$ in diameter. The mesentery was thickened and oedematous. The regional mesenteric lymph nodes were enlarged to $3 \mathrm{~cm}$ diameter and soft in consistency.

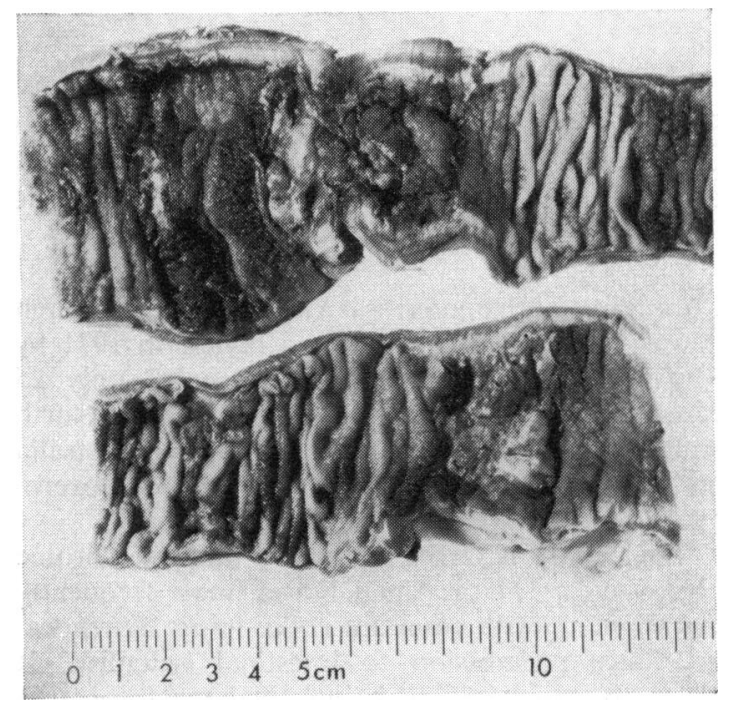

Fig 2 Chronic ulcerative enteritis. Multiple ulcers, varying in size, are present in the resected jejunum.

Histological examination showed a necrotizing ulceration extending in depth for a variable distance and in some instances involving the muscle coat (fig 3).

The fibrinopurulent exudate on the surface contained a mixture of Gram-positive cocci and bacilli but acid-fast organisms and fungi were not found. Fibrinoid change was prominent in the walls of small blood vessels in the necrotic parts of the bowel and there was a diffuse mixed inflammatory infiltrate composed of neutrophil and eosinophil leucocytes, plasma cells, and lymphocytes. The submucosa adjacent to the ulcers was thickened by fibroblastic connective tissue; scar tissue replacement of portion of the muscle coat was evidence of a chronic disease process. The mesenteric lymph nodes showed non-specific inflammation and reactive changes. Adjacent to one of the large ulcers there was a focus of necrotic mesenteric fat containing obliterated arteries.

Following discharge from hospital the patient was initially well and gained some weight. However, pain and vomiting later recurred despite a gluten- 


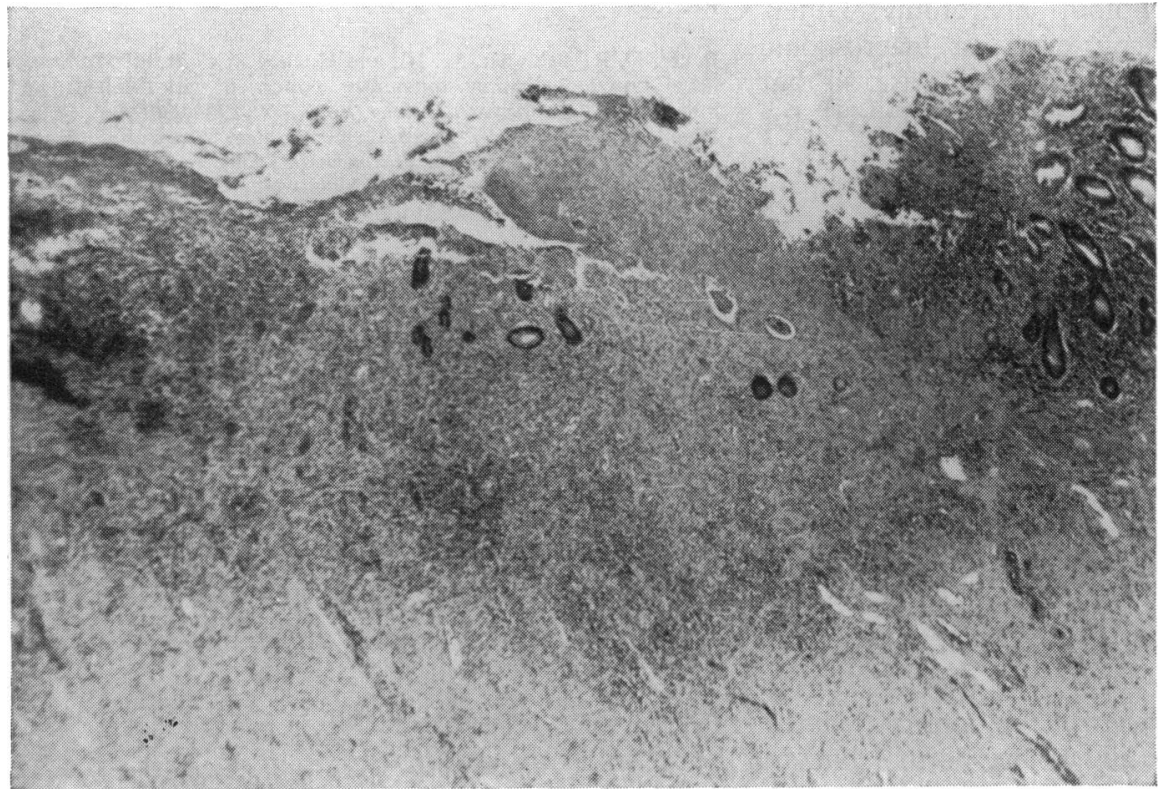

Fig 3 Chronic ulcerative enteritis. A few remaining glands can be seen in necrotic tissue of the ulcerated area. There is a diffuse infiltrate of inflammatory cells. $H \& E \times 100$ free diet and antibiotic therapy. She became depressed and was admitted to a psychiatric hospital. She died in October 1971 during insulin-shock therapy. Postmortem examination was not obtained.

\section{Discussion}

This case meets fully the clinical, radiological and histological criteria for the diagnosis of chronic ulcerative enteritis. There is clear evidence that atrophic jejunitis with malabsorption was present for some years before the onset of intestinal ulceration. This is shown by the history, initial biochemical, radiological, and biopsy findings, and the macroscopic appearances at the first laparotomy in July 1968. This appears to be the usual sequence, although some cases have come to medical attention only with the onset of symptoms due to the presence of jejunal ulcers.

There is no satisfactory explanation of the development of intestinal ulceration in some patients with atrophic jejunitis.

It does not seem to be secondary to vasculitis. The arteritis observed adjacent to the ulceration is probably a secondary effect, and there are no reports of vascular disease in other parts of the body.

Ulceration secondary to a chronic bacterial infection is a further possibility, and bacteria were observed in the ulcerated areas of mucosa in the present case. But this hypothesis does not explain facts such as the chronicity of the disease and clinical and histological differences from known bacterial ulcerative diseases of the small intestine due to organisms such as Salmonellae, Clostridia, and Mycobacterium tuberculosis.

The possibility of an ingested toxin is suggested by distribution of the ulcers. These are in most cases larger and more numerous in the proximal jejunum and often absent from the ileum, so that many cases have been reported as ulcerative jejunitis rather than ulcerative enteritis. However, no such toxin has been identified. Some preparations of potassium chloride are known to cause intestinal ulceration (Baker, Schrader, and Hitchcock, 1964), but these have not been mentioned in most reports of patients with ulcerative enteritis. The present patient did receive supplements of potassium chloride, but at laparotomy after cessation of this therapy there were no signs of ulceration. Nevertheless, the possibility of an allergic reaction to some ingested agent seems the least unlikely explanation of the distribution and pathology of the lesions and their occurrence in patients with gluten enteropathy.

The clinical problem presented by patients with chronic ulcerative enteritis is that of clinical deterioration with subacute intestinal obstruction in a patient with atrophic jejunitis. The differential diagnosis is from intestinal neoplasm, since this is also a recognized late complication of atrophic jejunitis (Joske, 1960; Read, 1970). There seems no 
way to resolve this without laparotomy. Differentiation may be difficult even on macroscopic inspection of the gut, as in the present case, so that the surgeon must obtain adequate material for histological examination.

The treatment of this disease is unknown, but in most recorded cases the prognosis is poor. No certain benefits appear to derive from steroid or antibiotic therapy, but the rarity of the condition makes definitive conclusions impossible. Surgery is indicated both for diagnosis and treatment of obstructing lesions.
References

Baker, D. R., Schrader, W. H., and Hitchcock, C. R. (1964). Smallbowel ulceration apparently associated with thiazide and potassium therapy. J. Amer. med. Ass., 190, 586-590.

Davidson, A. R. (1969). Recurrent benign ileal ulcer occurring with the coeliac syndrome. Brit. med. J., 3, 341.

Goulston, K. J., Skyring, A. P., and McGovern, V. J. (1965). Ulcerative jejunitis associated with malabsorption. Aust. Ann. Med., 14, 57-64.

Joske, R. A. (1960). Primary carcinoma of the jejunum with atrophic jejunitis and intestinal malabsorption. Gastroenterology, 38, 810-816.

Moritz, M., Moran, J. M., and Patterson, J. F. (1971). Chronic ulcerative jejunitis. Gastroenterology, 60, 96-102.

Read, A. E. (1970). Malignant disease and steatorrhoea. Modern Trends Gastroent., 4, 180-197.

\section{The July 1973 Issue}

\section{THE JULY 1973 ISSUE CONTAINS THE FOLLOWING PAPERS}

Postprandial concentrations of free and conjugated bile acids down the length of the normal human small intestine T. C. NORTHFIELD AND I. MCCOLL

Effects on small-intestinal function and structure induced by feeding a deconjugated bile salt MICHAEL GRACEY, JOHN PAPADIMITRIOU, VALERIE BURKE, JENNIFER THOMAS, AND GEOFFREY BOWER

The isolation, partial characterization, and subfractionation of human intestinal brush borders S. E. HOUGHTON AND C. F. MCCARTHY

Small intestinal beta-galactosidase activity in the horse M. C. ROBERTS, D. E. KIDDER, AND F. W. G. HILL

Phytohaemagglutinin-induced lymphocyte transformation in patients before and after resection of large intestinal cancer M. B. MCILLMURRAY, M. GRAY, AND M. J. S. LANGMAN

Studies of carcinoembryonic antigen activity of whole and extracted serum in ulcerative colitis $\mathbf{s}$. $\mathbf{K}$. KHOO, P. S. HUNT, AND I. R. MACKAY

Progressive increase in the functional $G$ cell mass with age in atrophic gastritis M. G. KORMAN, J. HANSKY, AND R. G. STRICKLAND

Histological changes in the gastric mucosa of chronic gastric ulcer patients treated with carbenoxolone E. THOMAS, P. HALL, AND I. G. HISLOP
Pyloric reflux and the healing of gastric ulcers J. B. COCKING AND P. GRECH

Hypersecretion of zymogen granules in the pathogenesis of cystic fibrosis JEANETTE BLOMFIELD, J. DASCALU, E. W. VAN LENNEP, AND J. M. BROWN

Jaundice after multiple halothane anaesthetics administered during the treatment of carcinoma of the uterus P. DAVIS AND C. D. HOLDSWORTH

Determinants of serum antipyrine half-lives in patients with liver disease R. A. BRANCH, CAROL M. HERBERT, AND ALAN E. READ

Experimental hepatic necrosis: Studies on coagulation abnormalities, plasma clearance, and organ distribution of ${ }^{125}$ I-labelled fibrinogen M. O. RAKE, P. T. FLUTE, G. PANNELL, K. B. SHILKIN, AND ROGER WILLIAMS

\section{Technique}

Protective finger device for use in endoscopic procedures MELVIN L. BUTLER

\section{Progress report The Lundh test OLIVER JAMES}

Progress report Perfusion of the pancreas T. SCRATCHERD AND R. M. CASE

Notes and activities

Copies are still available and may be obtained from the PUBLISHING MANAGER, BRITISH MEDICAL ASSOCIATION, TAVISTOCK SQUARE, LONDON, WC1H 9JR, price 87 $\frac{1}{2} \mathrm{p}$ 